\title{
INDUCTION SHOOTS FROM CALLUS OF CUCUMBER APPLE (Cucumis sp.) USING A COMBINATION OF BENZIL AMINO PURINE AND NAPHTHALENE ACETIC ACID CONCENTRATIONS IN VITRO
}

\section{Fransisca Natalia Erzalinda Mendrofa*, Nurcahyo Widyodaru Saputro, Lutfi Afifah}

Program Studi Agroteknologi, Fakultas Pertanian, Universitas Singaperbangsa Karawang Jl. HS. Ronggo Waluyo, Telukjambe Timur, Karawang, Jawa Barat, Indonesia 41361 *fransiscamendrofa@gmail.com ${ }^{1}$

Doi: 10.31943/mangiferaedu.v5i2.102

Received: August 9, 2020 Accepted: December 17, 2020 Published: January 31, 2021 Citation: Mendrofa, F. N. E., Saputro, N. W., \& Afifah, L. (2021). Induction Shoots From Callus of Cucumber Apple (Cucumis sp.) Using a Combination of Benzil Amino Purine and Naphthalene Acetic Acid Concentrations In Vitro. Jurnal Mangifera Edu, 5(2), 103-120.

\begin{abstract}
Research on indirect organogenesis of cucumber apple (Cucumis sp.) was conducted from March to May 2020. This study aims to find the best combination between Benzyl Amino Purine (BAP) and Naphthalene Acetic Acid (NAA) on the growth of cucumber apple (Cucumis) sp.) on Gamborg media (B5) by organogenesis. The callus used came from cucumber seeds explants with a concentration of NAA 2,0 mg/l $+B A P 0,2 \mathrm{mg} / \mathrm{l}$ using Murashige and Skoog media. The research method used is an experimental method with nonparametric statistics with 24 treatments repeated three times and analyzed descriptively using the Kruskal Wallis test. The results showed that the best treatment of cucumber apple shoots was the combination of NAA and BAP, namely the $B_{4} N_{2}$ treatment $(2,5$ ppm BAP + 0,20 ppm NAA) with shoot height $(0,45 \mathrm{~cm})$. At a single concentration, a concentration of 1 ppm BAP was able to provide a faster effect on shoot formation time, namely at 24 days after initiation (hsi) and the best response to shooting height $(0,5 \mathrm{~cm})$
\end{abstract}

Keywords: BAP, Callus, Gamborg, NAA, Organogenesis, and Shoots

\section{ABSTRAK}

Penelitian tentang organogenesis tidak langsung timun apel (Cucumis sp.) telah dilaksanakan pada bulan Maret sampai Mei 2020. Penelitian ini bertujuan untuk mendapatkan kombinasi terbaik antara Benzil Amino Purine (BAP) dan Naphthalene Acetic Acid (NAA) terhadap pertumbuhan tunas tanaman timun apel (Cucumis sp.) pada media Gamborg (B5) secara organogenesis. Kalus yang digunakan berasal dari eksplan biji timun apel dengan konsentrasi NAA 2,0 mg/l + BAP 0,2 mg/l menggunakan media Murashige dan Skoog. Metode penelitian yang digunakan adalah metode eksperimental dengan statistik nonparametrik dengan 24 perlakuan yang diulang sebanyak 3 kali serta dianalisis secara deskriptif menggunakan Uji Kruskal Wallis. Hasil penelitian menunjukkan terdapat pertumbuhan tunas timun apel perlakuan terbaik kombinasi NAA dan BAP yaitu pada perlakuan $B_{4} N_{2}(2,5$ ppm $B A P+0,20$ ppm NAA) dengan tinggi tunas $(0,45 \mathrm{~cm})$. Pada konsentrasi tunggal, konsentrasi 1 ppm BAP mampu memberikan pengaruh lebih cepat 
terhadap waktu pembentukan tunas yaitu pada 24 hari setelah inisiasi (hsi) dan respon tinggi tunas terbaik $(0,5 \mathrm{~cm})$

Kata Kunci: BAP, Gamborg, Kalus, NAA, Organogenesis, dan Tunas

\section{PENDAHULUAN}

Buah-buahan termasuk ke dalam jenis hortikultura yang banyak macamnya, salah satu buah yang dibudidayakan di Karawang, Jawa Barat adalah timun apel (Cucumis sp.). Menurut Saputro et al. (2020), Tanaman timun apel mempunyai bentuk buah yang menyerupai apel tetapi memiliki daging dan rasa buah yang mirip dengan melon, varietas khusus ini didistribusikan dari Jember, Karawang, dan ke daerah lain. Saat ini tidak ada informasi tentang evaluasi morfo-agronomi dalam timun apel, karena kurangnya data pada morfologi timun apel. Sehingga membenarkan perbedaan antara timun apel dengan melon dan mentimun karena kemiripan vegetatif. Hal ini menjadikan komoditas timun apel sangat potensial untuk diusahakan karena memiliki nilai ekonomi dan daya saing yang lebih tinggi (Mufida, 2018).

Berdasarkan alasan tersebut, maka perlu dicari alternatif untuk memperoleh bibit timun apel yang baik dan dapat dikembangkan secara luas di Indonesia dengan harga murah. Salah satu teknik yang diharapkan dapat digunakan untuk perbanyakan timun apel ini adalah teknik kultur jaringan. Menurut Purnamaningsih (2002), tanaman dengan teknik kultur jaringan dapat menghasilkan tanaman dalam jumlah yang banyakdan tanaman tersebut dapat diperbanyak setiap waktu sesuai kebutuhan. Kultur jaringan dapat dilakukan melalui dua jalur yaitu secara embriogenesis somatik dan organogenesis.

Penggandaan biakan secara embriogenesis somatik melalui beberapa tahapan, yaitu induksi sel dan kalus embriogenik, pendewasaan, perkecambahan, dan hardening (Purnamaningsih 2002), sedangkan pada organogenesis dilakukan pada sel-sel yang mampu memberikan tanggapan terhadap sinyal lingkungan maupun hormonal sehingga akan berakhir dengan terbentuknya organ berupa akar maupun tunas (Tyas et al., 2016). Penggandaan biakan secara organogenesis dibagi menjadi organogenesis langsung dan organogenesis tidak langsung (Surachman, 2011). Menurut Saptari (2017), pada organogenesis langsung, jaringan yang diinduksi akan langsung membentuk organ berupa tunas maupun akar, apabila terbentuk tunas eksplan dapat diinduksi perakarannya ketika proses pendewasaan. Sedangkan apabila akar yang tumbuh, tunas akan sulit untuk diinduksi. Pada organogenesis tidak langsung, prosesnya melalui tahapan pembentukan kalus terlebih 
dahulu yang kemudian diinduksi untuk membentuk tunas maupun akar (Rosmaina \& Aryani, 2015).

Respon organogenesis pada Cucurbitaceae sangat dipengaruhi oleh eksplan, media, dan zat pengatur tumbuh (Souza et al., 2006). Zat pengatur tumbuh yang diperlukan untuk pertumbuhan tunas pada media in vitro adalah auksin dan sitokinin. Menurut Karjadi \& Buchory (2007), perbandingan konsentrasi sitokinin lebih yang besar daripada konsentrasi auksin, maka akan menghasilkan pertumbuhan tunas dan daun, sebaliknya apabila konsentrasi sitokinin lebih rendah dari konsentrasi auksin, maka akan menstimulasi pada pertumbuhan akar. Sedangkan perbandingan konsentrasi sitokinin dan auksin yang seimbang akan menghasilkan pertumbuhan yang seimbang juga terhadap tunas, daun, dan akar.

Keberhasilan dalam kultur jaringan salah satunya ditentukan oleh media kultur jaringan yang merupakan tempat tumbuh bagi eksplan (Fauzy et al., 2016). Media yang banyak digunakan untuk perbanyakan secara organogenesis adalah media MS (Murashige and Skoog) dan Gamborg (Prayoga \& Sugiyono, 2010). Menurut Prayoga \& Sugiyono (2010), Media gamborg (B5) memiliki salah satu keunggulan yaitu kandungan garam mineral yang ada di dalam media B5 ternyata lebih rendah daripada media MS. Rendahnya kandungan garam mineral ini ternyata memberikan respon yang baik pada beberapa spesies tanaman salah satunya adalah spesies legume. Penggunaan medium MS dengan modifikasi medium menggunakan B5 telah dilakukan untuk meningkatkan multiplikasi dan ketegaran tanaman sebelum diaklimatisasi (Romeida et al., 2013). Hasil penelitian Karjadi \& Buchory (2007) menyatakan bahwa hasil terbaik penggunaan media B5 untuk tinggi plantlet bawang putih ada pada konsentrasi NAA $0 \mathrm{mg} / \mathrm{l}$ + BAP 2,5 mg/l. Maka dari itu media B5 diharapkan tepat, untuk pertumbuhan tunas timun apel secara in vitro.

Penelitian ini merupakan penelitian lanjutan dari penelitian tentang pertumbuhan kalus dari eksplan biji menggunakan media MS (Ayu, 2019). Tumbuhnya kalus ini merupakan langkah awal dalam perkembangan organogenesis tidak langsung yang kemudian akan berakhir dengan terbentuknya organ berupa tunas maupun akar.

\section{METODOLOGI PENELITIAN}

Penelitian ini dilaksanakan pada bulan Maret sampai Mei 2020 di Laboratorium Bioteknologi Tanaman Fakultas Pertanian Universitas Singaperbangsa Karawang dan pengamatan dilakukan di Jl. Melati Tengah Kecamatan Pondok Melati, Bekasi, Jawa Barat.Bahan yang di gunakan adalah kalus (Ayu, 2019), media B5, agar, gula, dan zat 
pengatur tumbuh (BAP dan NAA). Alat yang digunakan antara lain botol kultur, tempat penyimpanan kultur dilengkapi dengan cahaya dan suhu ruang.

Penelitian ini dirancang menggunakan uji statistik non-parametrik Kruskal-Wallis dengan 24 perlakuan. Masing-masing perlakuan terdiri atas 3 ulangan sehingga terdapat 72 satuan percobaan dengan 1 kalus untuk setiap ulangannya. Adapun perlakuan yang diberikan yaitu konsentrasi BAP dan NAA terhadap media B5.

1. Konsentrasi BAP (Benzyl Amino Purine) dengan 6 taraf yaitu :

a. $\quad \mathrm{B}_{0}=$ Konsentrasi BAP $0 \mathrm{ppm}$

b. $\mathrm{B}_{1}=$ Konsentrasi BAP 1,0 ppm

c. $\mathrm{B}_{2}=$ Konsentrasi BAP $1,5 \mathrm{ppm}$

d. $\mathrm{B}_{3}=$ Konsentrasi BAP 2,0 ppm

e. $\mathrm{B}_{4}=$ Konsentrasi BAP 2,5 ppm

f. $\mathrm{B}_{5}=$ Konsentrasi BAP 3,0 ppm

2. Konsentrasi NAA (Napthalene Amino Acid) dengan 4 taraf yaitu :

a. $\mathrm{N}_{0}=$ Konsentrasi NAA $0 \mathrm{ppm}$

b. $\mathrm{N}_{1}=$ Konsentrasi NAA $0,15 \mathrm{ppm}$

c. $\mathrm{N}_{2}=$ Konsentrasi NAA 0,20 ppm

d. $\mathrm{N}_{3}=$ Konsentrasi NAA $0,25 \mathrm{ppm}$

Tabel 1. Perlakuan Penelitian Kombinasi BAP dan NAA

\begin{tabular}{ccccc}
\hline Konsentrasi & \multicolumn{4}{c}{ Konsentrasi NAA $(\mathrm{N})$} \\
\cline { 2 - 5 } BAP (B) & 0,0 ppm $\left(\mathrm{N}_{0}\right)$ & $0,15 \mathrm{ppm}\left(\mathrm{N}_{1}\right)$ & $0,20 \mathrm{ppm}\left(\mathrm{N}_{2}\right)$ & $0,25 \mathrm{ppm}\left(\mathrm{N}_{3}\right)$ \\
\hline $0,0 \mathrm{ppm}\left(\mathrm{B}_{0}\right)$ & $\mathrm{B}_{0} \mathrm{~N}_{0}$ & $\mathrm{~B}_{0} \mathrm{~N}_{1}$ & $\mathrm{~B}_{0} \mathrm{~N}_{2}$ & $\mathrm{~B}_{0} \mathrm{~N}_{3}$ \\
$1,0 \mathrm{ppm}\left(\mathrm{B}_{1}\right)$ & $\mathrm{B}_{1} \mathrm{~N}_{0}$ & $\mathrm{~B}_{1} \mathrm{~N}_{1}$ & $\mathrm{~B}_{1} \mathrm{~N}_{2}$ & $\mathrm{~B}_{1} \mathrm{~N}_{3}$ \\
$1,5 \mathrm{ppm}\left(\mathrm{B}_{2}\right)$ & $\mathrm{B}_{2} \mathrm{~N}_{0}$ & $\mathrm{~B}_{2} \mathrm{~N}_{1}$ & $\mathrm{~B}_{2} \mathrm{~N}_{2}$ & $\mathrm{~B}_{2} \mathrm{~N}_{3}$ \\
$2,0 \mathrm{ppm}\left(\mathrm{B}_{3}\right)$ & $\mathrm{B}_{3} \mathrm{~N}_{0}$ & $\mathrm{~B}_{3} \mathrm{~N}_{1}$ & $\mathrm{~B}_{3} \mathrm{~N}_{2}$ & $\mathrm{~B}_{3} \mathrm{~N}_{3}$ \\
$2,5 \mathrm{ppm}\left(\mathrm{B}_{4}\right)$ & $\mathrm{B}_{4} \mathrm{~N}_{0}$ & $\mathrm{~B}_{4} \mathrm{~N}_{1}$ & $\mathrm{~B}_{4} \mathrm{~N}_{2}$ & $\mathrm{~B}_{4} \mathrm{~N}_{3}$ \\
$3,0 \mathrm{ppm}\left(\mathrm{B}_{5}\right)$ & $\mathrm{B}_{5} \mathrm{~N}_{0}$ & $\mathrm{~B}_{5} \mathrm{~N}_{1}$ & $\mathrm{~B}_{5} \mathrm{~N}_{2}$ & $\mathrm{~B}_{5} \mathrm{~N}_{3}$ \\
\hline
\end{tabular}

Data hasil dari setiap pengamatan akan dianalisis secara deskriptif dan statistik nonparametrik dengan menggunakan uji Kruskal Wallis pada taraf 5\%. Apabila nilai $\mathrm{H}>$ nilai tabel chi square maka $\mathrm{H}$ nol $\left(\mathrm{H}_{0}\right)$ ditolak dan sebaliknya apabila nilai $\mathrm{H}<$ nilai tabel chi square maka H nol $\left(\mathrm{H}_{0}\right)$ diterima. Menurut Furqon (1999) uji Kruskal Wallis (uji H) sejenis dengan uji Analysis of Variance (ANOVA). Berikut merupakan rumus uji Kruskal Wallis (Siegel et al., 1997) :

$$
\mathrm{H}=\frac{12}{N(N+1)} \sum_{j}^{k} \frac{R i^{2}}{n j}-3(\mathrm{~N}+1)
$$

Keterangan : 
$\mathrm{k} \quad$ : Banyak sampel

$\mathrm{R}_{\mathrm{i}} \quad$ : Jumlah peringkat pada kelompok $\mathrm{i}$

$\mathrm{n}_{j} \quad$ : Banyak kasus dalam sampel ke-j

$\mathrm{N}: \sum n_{i}=$ Banyak kasus dalam semua sampel

$\sum_{j=1}^{k}$ : Menjumlahkan seluruhnya k sampel (kolom-kolom) mendekati distribusi

chi-kuadrat dengan $\mathrm{db}=\mathrm{k}-1$ untuk ukuran sampel $\left(\mathrm{n}_{j}\right)$ yang cukup besar.

Induksi tunas dilakukan dengan cara mensubkultur kalus timun apel (Cucumis sp.) kemudian memindahkannya pada media regenerasi. Setelah itu dilakukan pengamatan terhadap warna tunas, waktu muncul tunas, tinggi tunas dan pertambahan diameter kalus.

\section{Parameter Penelitian}

1. Warna tunas diamati secara visual pada akhir pengamatan dengan menggunakan skoring menurut Yuniati et al. (2018):

\section{Skor 0 : Warna coklat;}

Skor 1 : Warna putih kecoklatan;

Skor 2 : Warna putih;

Skor 3 : Warna kuning;

Skor 4 : Warna hijau muda;

Skor 5 : Warna hijau;

Skor 6 : Warna hijau tua.

2. Waktu muncul tunas, pengamatan dilakukan dengan mencatat hari pertama kali tunasmuncul. Munculnya tunas ditandai dengan adanya tonjolan tunas berwarna putih kehijauan pada permukaan kalus dan memiliki panjang mencapai 2 mm (Ardiana, 2009). Pengamatan dilakukan setiap hari untuk mengetahui waktu muncul tunas.

3. Tinggi tunas, pengamatan dilakukan dengan cara mengukur tinggi tunas dari permukaan media sampai titik tumbuh utama (Ardiana, 2009). Pengamatan dilakukan setiap tiga hari sekali dimulai pada 3 hsi sampai 60 hsi.

4. Pertambahan diameter kalus, diukur dengan cara mengukur diameter kalus dengan penggaris satuan sentimeter $(\mathrm{cm})$ (Ubudiyah \& Tutik, 2013). Pengukuran dilakukan setiap 3 hari selama 2 bulan menggunkan penggaris. Cara perhitungan diameter kalus sebagai berikut: 


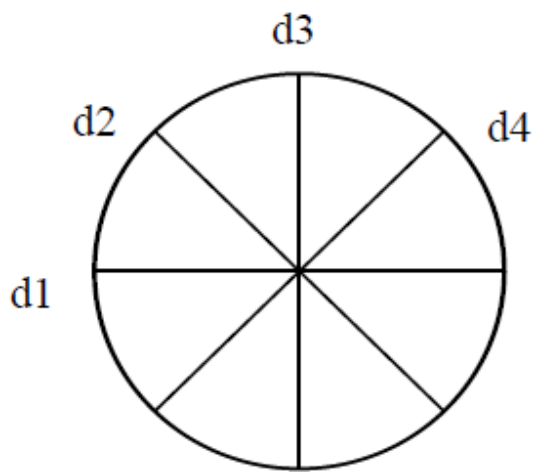

Gambar 1. Cara Peritungan Arah Radial (Lestari et al., 2018)

Rata-rata diameter radial $(\overline{\mathrm{d}})=\frac{\mathrm{d} 1+\mathrm{d} 2+\mathrm{d} 3+\mathrm{d} 4}{4}$

Keterangan:

$\mathrm{d}:$ diameter

$\overline{\mathrm{d}}:$ diameter rata-rata

di : diameter ke-i, i = 1, 2, 3, ...i

\section{HASIL DAN PEMBAHASAN}

\section{Warna Tunas}

Pengamatan warna tunas dilakukan selama dua bulan dengan didasarkan pada skoring 0-6 (Yuniati et.al., 2018). Dapat dilihat pada Tabel 2.

Tabel 2. Skoring warna tunas timun apel yang ditanam secara in vitro pada setiap perlakuan saat $60 \mathrm{hsi}$

\begin{tabular}{ccccc}
\hline Konsentrasi & \multicolumn{4}{c}{ Konsentrasi NAA (N) } \\
\cline { 2 - 5 } BAP $(\mathbf{B})$ & $0,0 \mathrm{ppm}\left(\mathrm{N}_{0}\right)$ & $0,15 \mathrm{ppm}\left(\mathrm{N}_{1}\right)$ & $0,20 \mathrm{ppm}\left(\mathrm{N}_{2}\right)$ & $0,25 \mathrm{ppm}\left(\mathrm{N}_{3}\right)$ \\
\hline $0,0 \mathrm{ppm}\left(\mathrm{B}_{0}\right)$ & - & - & - & 2 \\
$1,0 \mathrm{ppm}\left(\mathrm{B}_{1}\right)$ & 2 & - & 1 & - \\
$1,5 \mathrm{ppm}\left(\mathrm{B}_{2}\right)$ & - & - & 1 & 1 \\
$2,0 \mathrm{ppm}\left(\mathrm{B}_{3}\right)$ & 3 & - & 2 & 2 \\
2,5 ppm $\left(\mathrm{B}_{4}\right)$ & 2 & - & 3 & - \\
3,0 ppm (B) & 2 & - & - & - \\
Keterangan : (-) tidak tumbuh tunas; (0) coklat; (1) putih kecoklatan; (2) putih; (3) kuning; (4) hijau \\
muda; (5) hijau; (6) hijau tua
\end{tabular}

Warna tunas yang terbentuk adalah putih kecoklatan, putih, dan kuning (Tabel 2). Peningkatan pada warna tidak terjadi dimungkinkan karena adanya penambahan NAA pada media kultur. Kemungkinan lain terjadi karena adanya auksin endogen sehingga kerja BAP dalam mendorong pembentukan klorofil menjadi terhambat. Sesuai dengan yang diungkapkan oleh Widyawati (2010), sitokinin mendukung pembentukan klorofil sedangkan auksin bekerja untuk menghambatnya. Kenaikan kadar auksin akan menurunkan kandungan klorofil (Khalida \& Noli, 2019). Penurunan kandungan klorofil ini diduga juga karena 
adanya pengaruh auksin pada metabolisme karbohidrat, apabila metabolisme karbohidrat terganggu maka sintesis klorofil juga akan terganggu (Yuniati et al., 2018).

Hasil penelitian menunjukan adanya warna kuning pada tunas yang terbentuk. Menurut Fauzy et al. (2016), perubahan warna tersebut diduga sebagai bentuk respon stres kalus terhadap radiasi sinar gamma, sehingga menstimulasi enzim tertentu untuk membentuk senyawa fenol sebagai bentuk pertahanan diri yang mengakibatkan terjadinya degradasi klorofil pada sel-sel kalus. Kemungkinan lain terjadinya reduksi klorofil pada kalus yaitu disebabkan karena proses penuaan pada sel-sel kalus. Proses senesen pada kultur in vitro dapat terjadi melalui bentuk yang berbeda-beda seperti daun menguning dan kalus berubah warna menjadi kuning kecoklatan, kekurangan nutrisi dari media pada kultur juga merupakan penyebab senesen.

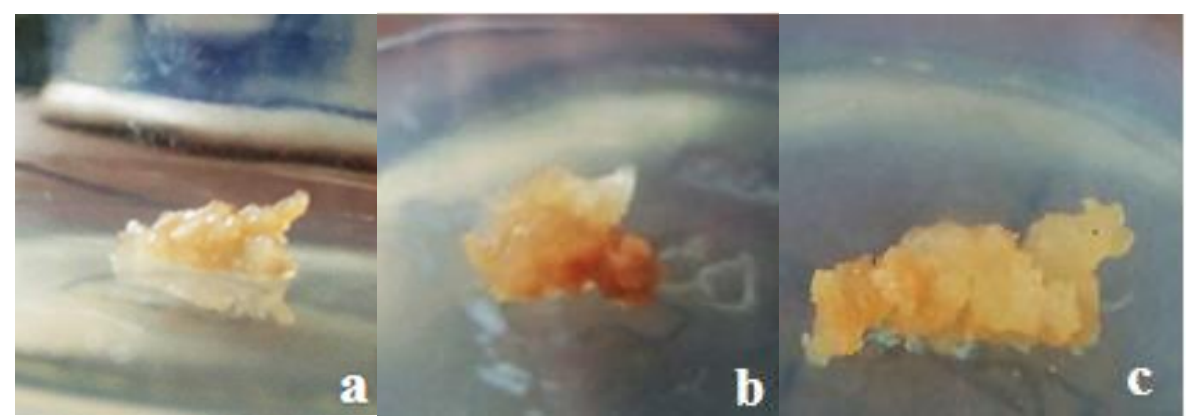

Gambar 2. Warna tunas yang terbentuk pada $60 \mathrm{HSI}$, a. Warna putih kecoklatan pada $B_{1} \mathbf{N}_{2}$ $\left(1,0 \mathrm{ppm}\right.$ BAP + 0,20 ppm NAA), b. Warna putih pada $B_{1} \mathrm{~N}_{0}(\mathrm{BAP} 1 \mathrm{ppm})$, c. Warna kuning $\mathrm{B}_{3} \mathrm{~N}_{0}(2,0 \mathrm{ppm} \mathrm{BAP})$

Menurut Toharah et al. (2015) dan Souza et al. (2006), kemampuan untuk regenerasi dan organogenesis eksplan Cucurbitaceae khususnya melon dipengaruhi oleh jenis eksplan, genotipe, dan zat pengatur tumbuh, baik antara auksin dan sitokinin tidak sesuai. Sehingga kemungkinan besar tidak terjadi peningkatan warna tunas ini disebabkan karena keseimbangan zat pengatur tumbuh yang ada di dalam sel dan di luar sel belum terpenuhi.

\section{Waktu Muncul Tunas}

Pembentukan tunas dari kalus dimulai dengan terbentuknya tonjolan-tonjolan sebesar 0,2 cm berwarna putih kehijauan pada kalus yang telah terbentuk (Ardiana, 2009). Tonjolan yang terbentuk kemudian akan mulai terdiferensiasi dan berkembang menjadi calon tunas. Tonjolan-tonjolan tersebut kemungkinan besar merupakan tunas adventif, sesuai pernyataan Rohayati (2012), pembentukan tunas adventif dimulai dengan pembentukan kalus. Kalus akan tumbuh dan berkembang, selanjutnya diikuti dengan pembentukan tunas adventif. Tunas adventif terbentuk karena adanya pengaruh dari totipotensi sel dan kompetensinya, di mana setiap sel memiliki kemampuan aktif untuk 
beregenerasi membentuk tanaman secara utuh. Menurut Sisharmini et al. (2010) menyatakan bahwa tidak semua kalus yang berwarna hijau dapat memunculkan tonjolan tunas.

Berdasarkan hasil penelitian diketahui bahwa pemberian BAP (Benzil Amino Purine) dan NAA (Naphthalene Acetic Acid) pada berbagai konsentrasi memiliki pengaruh yang berbeda terhadap kecepatan muncul tunas. Data rata-rata munculnya tunas seluruh perlakuan tersaji pada Tabel 3.

Tabel 3. Waktu muncul tunas yang ditanam secara in vitro selama penelitian berlangsung pada setiap perlakuan

\begin{tabular}{cccccc}
\hline & Konsentrasi & \multicolumn{5}{c}{ Konsentrasi NAA (N) } \\
\cline { 2 - 6 } Waktu & BAP $(\mathbf{B})$ & $0,0 \mathrm{ppm}\left(\mathrm{N}_{0}\right)$ & $0,15 \mathrm{ppm}\left(\mathrm{N}_{1}\right)$ & $0,20 \mathrm{ppm}\left(\mathrm{N}_{2}\right)$ & $0,25 \mathrm{ppm}\left(\mathrm{N}_{3}\right)$ \\
\cline { 2 - 6 } Muncul & $0,0 \mathrm{ppm}\left(\mathrm{B}_{0}\right)$ & - & - & - & 36 \\
Tunas & $1,0 \mathrm{ppm}\left(\mathrm{B}_{1}\right)$ & 24 & - & 30 & - \\
(hsi) & $1,5 \mathrm{ppm}\left(\mathrm{B}_{2}\right)$ & - & - & 30 & 30 \\
& $2,0 \mathrm{ppm}\left(\mathrm{B}_{3}\right)$ & 36 & - & 45 & 51 \\
& $2,5 \mathrm{ppm}\left(\mathrm{B}_{4}\right)$ & 30 & - & 33 & - \\
& $3,0 \mathrm{ppm}\left(\mathrm{B}_{5}\right)$ & 27 & - & - & - \\
\hline
\end{tabular}

Keterangan: (-) tidak tumbuh tunas

Hasil penelitian (Tabel 3) dengan perlakuan tunggal BAP memberikan hasil terbaik rata-rata muncul tunas pada 24 hsi yaitu perlakuan $\mathrm{B}_{1} \mathrm{~N}_{0}(1 \mathrm{ppm} \mathrm{BAP})$ pada dan terendah perlakuan $\mathrm{B}_{3} \mathrm{~N}_{0}(2,0 \mathrm{ppm}$ BAP) pada 36 hsi. Selanjutnya pada perlakuan tunggal NAA, hanya satu perlakuan yang membentuk tunas yaitu perlakuan $\mathrm{B}_{0} \mathrm{~N}_{3}(0,25$ ppm NAA) pada 36 hsi. Pada perlakuan kombinasi BAP dan NAA memberikan hasil rata-rata awal muncul tunas tercepat pada 30 hsi pada perlakuan $\mathrm{B}_{1} \mathrm{~N}_{2}(1,0 \mathrm{ppm} \mathrm{BAP}+0,20 \mathrm{ppm} \mathrm{NAA}), \mathrm{B}_{2} \mathrm{~N}_{2}(1,5$ ppm BAP $+0,20$ ppm NAA) dan $\mathrm{B}_{2} \mathrm{~N}_{3}(1,5$ ppm BAP $+0,25$ ppm NAA). Sedangkan perlakuan $\mathrm{B}_{3} \mathrm{~N}_{3}(2,0$ ppm $\mathrm{BAP}+0,25$ ppm NAA) merupakan perlakuan kombinasi dengan waktu muncul tunas terendah yaitu pada 51 hsi.

Penelitian Lidyawati et al. (2012), menyatakan bahwa media dengan penambahan 1,0 ppm BAP dengan kombinasi 0,1 ppm IAA berpengaruh nyata terhadap waktu pembentukan serta peningkatan tunas dan daun pada kecambah steril dari biji melon. Menurut penelitian Keng \& Hoong (2005), bahwa auksin tidak dibutuhkan untuk proliferasi tunas pada eksplan buku muskmelon, karena media dengan tambahan BAP dapat digunakan sebagai media proliferasi. Sitokinin khususnya BAP dibutuhkan muskmelon untuk induksi pembentukan dan perbanyakan tunas. Melon berkerabat dengan dengan timun apel, sehingga kemungkinan besar tunas timun apel dapat tumbuh tanpa adanya penambahan auksin pada media.

Berdasarkan (Tabel 3) menunjukan rata-rata saat pertama kali muncul tunas tercepat yaitu pada perlakuan $\mathrm{B}_{1} \mathrm{~N}_{0}(1 \mathrm{ppm} \mathrm{BAP})$ pada umur 24 hsi. Hasil ini sama dengan penelitian 
yang sudah dilakukan oleh Lidyawati et al. (2012) dalam kaitannya dengan waktu munculnya tunas, menyatakan bahwa pemberian BAP 1 ppm sudah dapat menginduksi tunas melon dengan cepat pada umur 4 hsi.

Kristanti et al. (2013) menyatakan bahwa pada beberapa tanaman membutuhkan waktu yang cukup lama untuk beregenerasi, karena sitokinin endogen pada tanaman tidak mencukupi untuk pembentukan tunas. Sedangkan, hasil penelitian menunjukkan bahwa beberapa perlakuan dengan menggunakan BAP maupun tanpa BAP dapat memunculkan tunas. Hal ini mengindikasikan bahwa waktu kemunculan tunas tidak bergantung pada penambahan sitokinin eksogen. Kemungkinan besar bahwa kandungan sitokinin endogen pada kalus Cucumis sp. sudah mencukupi untuk pembentukan tunas. Hal ini juga ditegaskan oleh Karjadi \& Buchory (2007) bahwa ketepatan ZPT yang ditambahkan sangat penting dalam organogenesis, bila pucuk adventif muncul pada media dengan konsentrasi BAP yang lebih rendah, berarti ada kemungkinan terdapat sitokinin endogen yang sudah mencukupi, sehingga tidak diperlukan penambahan sitokinin dari luar. Sehingga hal ini berkaitan dengan interaksi ZPT yang digunakan dengan zat-zat endogen yang terdapat dalam jaringan tumbuhan. Sujatmiko et al. (2012) menyatakan bahwa penggunaan sitokinin eksogen dalam jumlah besar dapat mengubah keseimbangan hormon tanaman sehingga sel-sel tidak terdiferensiasi dengan teratur menyebabkan pembentukan kalus.

Walaupun demikian perlakuan dengan penggunaan hormon BAP pada penelitian dapat mempercepat awal kemunculan tunas. Sesuai dengan pernyataan Lidyawati et al. (2012) penggunaan BAP menghasilkan perbedaan yang nyata terhadap perlakuan tanpa pemberian BAP, konsentrasi BAP yang semakin meningkat pada tanaman melon akan mempercepat waktu pembentukan tunas.

Penambahan NAA pada penelitian ini tidak mampu mempercepat kemunculan tunas. Terlihat bahwa dengan semakin meningkatnya penambahan konsentrasi NAA, pengaruh hambatannya terhadap saat kemunculan tunas terlihat bervariasi (Tabel 3). Hal ini sejalan dengan penelitian Keng \& Hoong (2006), yang menyatakan bahwa penambahan auksin seperti NAA pada media MS $+8 \mathrm{mg} / \mathrm{l}$ BA tidak memberikan pengaruh yang nyata dalam pembentukan tunas pada eksplan nodal muskmelon.

Perbedaan formulasi komposisi medium juga memberikan pengaruh yang berbeda terhadap tanaman (Romeida et al., 2013). Menurut Romeida et al. (2013) komposisi pada media B5 mengandung beberapa konsentrasi senyawa organik yang lebih tinggi jika dibandingkan dengan komposisi media MS, perbandingannya yaitu konsentrasi Nicotinic acid 2 kali lebih tinggi, Thiamin-H 20 kali lebih tinggi, dan Pyridoxine-HCl 10 kali lebih 
tinggi. Setelah membandingkan media B5 dan media MS, terlihat bahwa pada media MS memiliki kelebihan yaitu mengandung asam amino Glycine dengan konsentrasi $2 \mathrm{mg} / \mathrm{l}$ sementara pada media B5 tidak terdapat asam amino Glycine.

Beberapa jenis tanaman sangat membutuhkan asam amino sebagai sumber $\mathrm{NH}^{2-}$ salah satunya adalah wortel. Asam amino berfungsi sebagai buffer yang mampu menjaga kestabilan $\mathrm{pH}$ medium terutama dalam menginduksi pembentukan embrio somatiknya (Romeida et al., 2013). Sehingga kemungkinan besar timun apel membutuhkan asam amino Glycine untuk pertumbuhan tunas secara organogenesis tidak langsung agar pertumbuhan tunas lebih optimal. Menurut Sucandra et al., (2015) penambahan asam amino Glycine dengan konsentrasi $2 \mathrm{mg} / \mathrm{l}$ dapat meningkatkan pertumbuhan sel tanaman dengan baik, karena penambahan glycine dalam media kultur jaringan dapat melengkapi vitamin sebagai sumber bahan organik.

\section{Tinggi Tunas}

Pengukuran tinggi tunas dilakukan selama 3 hari sekali sampai dengan 60 hsi. Hasil pengukuran diuji menggunakan uji Kruskal Wallis didapatkan dengan perhitungan. Nilai Tabel $\mathrm{H}$ dibandingkan dengan nilai Tabel Chi-square dimana jika $\mathrm{H}$ lebih kecil dari Tabel Chi-square maka $\mathrm{H}_{0}$ diterima dan $\mathrm{H}_{1}$ ada pertumbuhan tunas tanaman timun apel. Namun, jika $\mathrm{H}$ lebih besar dari Tabel Chi-square maka $\mathrm{H}_{0}$ ditolak dan $\mathrm{H}_{1}$ tidak ada pertumbuhan tunas timun apel. Berdasarkan hasil uji Kruskal Wallis diperoleh hasil seperti yang dicantumkan pada Tabel 4.

Tabel 4. Hasil nilai H pada setiap hsi

\begin{tabular}{cccc}
\hline hsi & Nilai $\mathbf{H}$ & Tabel chi square & Kesimpulan $\mathbf{H}_{\mathbf{0}}$ \\
\hline $\mathbf{3 0}$ & 0 & 14.07 & Diterima \\
$\mathbf{3 3}$ & 0 & 15.51 & Diterima \\
$\mathbf{3 6}$ & 2.54 & 15.51 & Diterima \\
$\mathbf{3 9}$ & 2.57 & 15.51 & Diterima \\
$\mathbf{4 2}$ & 2.60 & 15.51 & Diterima \\
$\mathbf{4 5}$ & 3.94 & 16.92 & Diterima \\
$\mathbf{4 8}$ & 5.42 & 16.92 & Diterima \\
$\mathbf{5 1}$ & 8.46 & 18.31 & Diterima \\
$\mathbf{5 4}$ & 10.18 & 18.31 & Diterima \\
$\mathbf{5 7}$ & 8.58 & 18.31 & Diterima \\
$\mathbf{6 0}$ & 7.18 & 18.31 & Diterima \\
\hline
\end{tabular}

Keterangan : jika nilai $\mathrm{H}<$ Tabel chi square maka $\mathrm{H}_{0}=$ diterima Nilai $\mathrm{H}>$ Tabel chi square maka $\mathrm{H}_{0}=$ ditolak Chi-square pada $5 \%$

Pada 30 hsi sampai dengan 60 hsi diperoleh kesimpulan $\mathrm{H}_{0}$ diterima, dimana apabila $\mathrm{H}_{0}$ diterima maka dapat disimpulkan bahwa ada pertumbuhan tunas tanaman timun apel pada 
hsi ke-30 sampai dengan hsi ke-60. Grafik pengamatan tinggi tunas pada beberapa perlakuan yang membentuk tunas pada 60 hari setelah inisiasi (hsi) dapat dilihat pada Gambar 2.

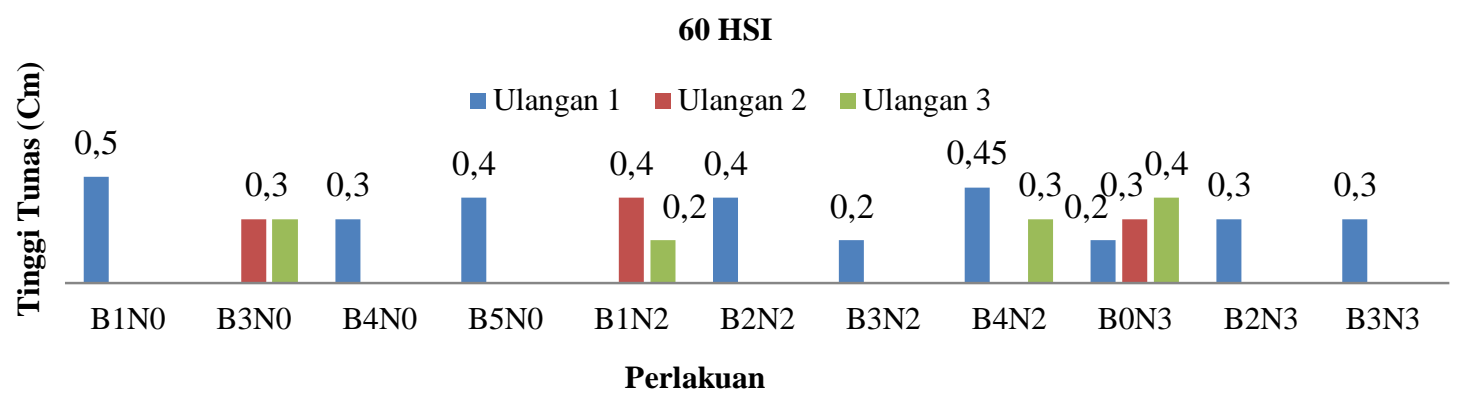

Gambar 3. Grafik tinggi tunas pada beberapa perlakuan yang terbentuk pada $60 \mathrm{hsi}, \mathrm{B}_{1} \mathrm{~N}_{\mathbf{0}}(1$ ppm BAP); B $_{3} \mathrm{~N}_{0}\left(2 \mathrm{ppm}\right.$ BAP); $\mathbf{B}_{4} \mathrm{~N}_{0}\left(2,5 \mathrm{ppm}\right.$ BAP); $\mathrm{B}_{5} \mathrm{~N}_{0}\left(3 \mathrm{ppm}\right.$ BAP); $\mathrm{B}_{1} \mathbf{N}_{2}(1 \mathrm{ppm}$ BAP + 0,20 ppm NAA); $B_{2} \mathbf{N}_{2}(1,5$ ppm BAP + 0,20 ppm NAA $) ; B_{3} N_{2}(2$ ppm BAP + 0,20 ppm NAA); $\mathrm{B}_{4} \mathrm{~N}_{2}(2,5 \mathrm{ppm} \mathrm{BAP}+0,20 \mathrm{ppm} \mathrm{NAA}) ; \mathrm{B}_{0} \mathrm{~N}_{3}(0,25 \mathrm{ppm} \mathrm{NAA}) ; \mathrm{B}_{2} \mathrm{~N}_{3}(1,5 \mathrm{ppm}$ $\mathrm{BAP}+0,25 \mathrm{ppm} \mathrm{NAA}) ; \mathrm{B}_{3} \mathrm{~N}_{3}(2 \mathrm{ppm} \mathrm{BAP}+0,25 \mathrm{ppm}$ NAA $)$

Pada Gambar 3. Perlakuan tunggal BAP memberikan hasil tinggi tunas terbaik pada perlakuan $\mathrm{B}_{1} \mathrm{~N}_{0}$ (1 ppm BAP) dan terendah pada perlakuan $\mathrm{B}_{3} \mathrm{~N}_{0}\left(2,0\right.$ ppm BAP) dan $\mathrm{B}_{4} \mathrm{~N}_{0}$ (2,5 ppm BAP). Selanjutnya perlakuan tunggal NAA pada $\mathrm{B}_{0} \mathrm{~N}_{3}(0,25 \mathrm{ppm}$ NAA) menumbuhkan tunas pada semua ulangan tetapi untuk tinggi tunas bervariasi. Sedangkan pada perlakuan kombinasi NAA dan BAP memberikan hasil terbaik terhadap tinggi tunas pada perlakuan $\mathrm{B}_{4} \mathrm{~N}_{2}\left(2,5\right.$ ppm BAP $+0,20$ ppm NAA) dan terendah pada perlakuan $\mathrm{B}_{3} \mathrm{~N}_{2}$ $(2,0$ ppm BAP $+0,20$ ppm NAA).

Hasil pengamatan organogenesis tanaman timun apel (Cucumis sp.) menunjukkan bahwa kalus mampu membentuk tunas dengan penambahan NAA dan BAP yaitu pada perlakuan $\mathrm{B}_{4} \mathrm{~N}_{2}(2,5 \mathrm{ppm} \mathrm{BAP}+0,20 \mathrm{ppm} \mathrm{NAA})$. Kombinasi NAA dan BAP menunjukan bahwa kedua perlakuan saling mendukung satu sama lainya dan mampu mempengaruhi pola aktivitas fisiologi tanaman. Hasil penelitian menyatakan bahwa apabila ada dua faktor yang diteliti dan salah satu faktor lebih kuat pengaruhnya dibandingkan dengan faktor lainya, maka faktor yang lemah akan tertutupi. Hal ini terjadi karena masing-masing faktor mempunyai sifat dan kerja yang berbeda dalam mendukung pertumbuhan dalam suatu tanaman (Kurniawan et al., 2019). Sesuai dengan pernyataan Paramartha et al. (2012), sitokinin memacu pembelahan sel dimana ketika rasio antara auksin dan sitokinin seimbang akan tumbuh sel-sel maristem yang terus membelah dan berkembang membentuk organ.

Walaupun demikian hasil tinggi tunas terbaik ada pada perlakuan tunggal yaitu pada konsentrasi 1 ppm BAP $\left(\mathrm{B}_{1} \mathrm{~N}_{0}\right)$ yang dapat merespon dan menghasilkan tunas yang paling tinggi diantara perlakuan lainnya. Hasil ini sama dengan penelitian yang sudah dilakukan oleh Lidyawati et al. (2012) melaporkan bahwa pemberian perlakuan dengan menggunakan 
1 ppm BAP dapat merespon dan menghasilkan tunas dan daun yang optimal dibanding perlakuan lainnya pada tanaman melon. Makin tinggi konsentrasi BAP tunas yang dibentuk akan semakin banyak.

Terlihat bahwa tunas mampu tumbuh pada beberapa perlakuan yang diberikan (Gambar 4). Menurut Purita et al. (2017), penggunaan zat pengatur tumbuh dalam subkultur pada batas-batas tertentu mampu merangsang pertumbuhan, namun dapat bersifat sebagai penghambat apabila digunakan melebihi konsentrasi optimum. Kemampuan sel-sel muda pada kalus adalah untuk menyerap hara lebih rendah, sedangkan konsentrasi hara yang lebih tinggi pada media dapat menghambat penyerapan hara, sehingga mengurangi kemampuan kalus untuk tumbuh.

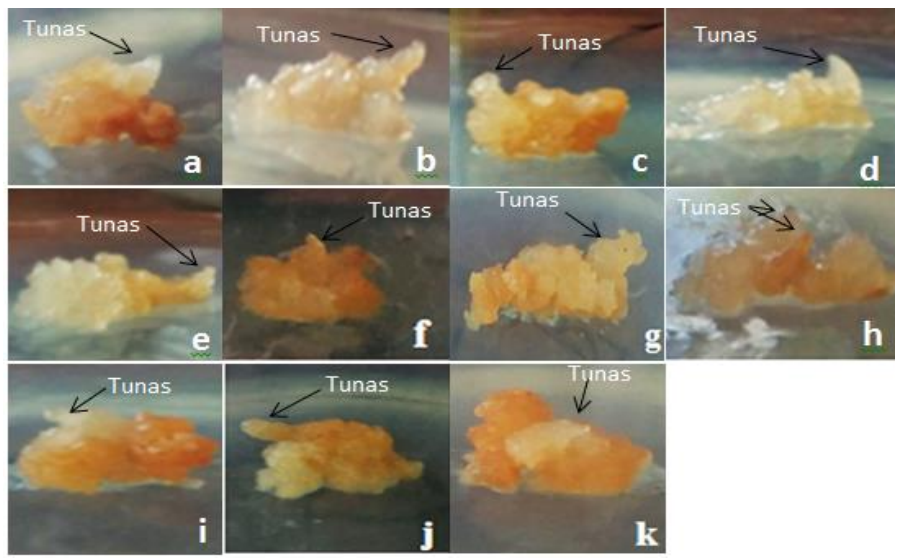

Gambar 4. Tunas pada beberapa perlakuan saat $60 \mathrm{HSI}$, a. $\mathrm{B}_{1} \mathrm{~N}_{\mathbf{0}}(\mathrm{BAP} 1 \mathrm{ppm})$, b. $\mathbf{B}_{1} \mathrm{~N}_{2}(1,0$ ppm BAP + 0,20 ppm NAA $)$, c. $B_{3} \mathrm{~N}_{2}(2 \mathrm{ppm} B A P+0,20 \mathrm{ppm} N A A)$, d. $\mathbf{B}_{5} \mathrm{~N}_{0}(3,0 \mathrm{ppm}$ BAP), e. $B_{3} N_{3}\left(2,0\right.$ ppm BAP + 0,25 ppm NAA), f. $B_{2} N_{2}(1,5$ ppm BAP + 0,20 ppm NAA), g. $B_{3} N_{0}(2,0$ ppm BAP $)$, h. $B_{2} \mathrm{~N}_{3}(1,5 \mathrm{ppm} B A P+0,25 \mathrm{ppm} N A A)$, i. $\mathrm{B}_{0} \mathrm{~N}_{3}(0,25 \mathrm{ppm} \mathrm{NAA})$, j. $\mathrm{B}_{4} \mathrm{~N}_{2}(2,5 \mathrm{ppm}$ BAP + 0,20 ppm NAA $), \mathrm{k} . \mathrm{B}_{4} \mathrm{~N}_{0}(2,5 \mathrm{ppm} \mathrm{BAP})$

Penambahan tinggi tunas pada penelitian ini semuanya mengalami pelambatan. Menurut Muliati et al., (2017), hal ini kemungkinan berhubungan dengan kemampuan sel untuk memacu diferensiasi tunas sehingga kalus mempunyai batas fisiologi untuk dapat berdiferensiasi menjadi organ. Ardiana (2009) melaporkan bahwa pemberian 0,50 ppm BAP menunjukkan respon terbaik terhadap panjang tunas melon, namun pada pemberian 1-1,50 ppm BAP, justru menghambat panjang tunas melon. Hal ini juga sejalan dengan pernyataan Widyastuti (2017), yang melaporkan bahwa konsentrasi BAP yang terlalu tinggi akan merusak jaringan tanaman sehingga pertumbuhan dan pembentukan buku tunas berkurang serta dapat menghambat pembesaran sel atau dapat mengalami stagnasi.

Stagnasi merupakan suatu keadaan eksplan dimana kalus tersebut tidak mati tetapi tidak tumbuh dari mulai tanam sampai kurun waktu tertentu (Syabana et al., 2017). Selama penelitian, stagnasi pada tunas diduga karena faktor dari media yang digunakan. Hal ini sesuai dengan pernyataan Arimarsetiowati (2012), yang menyatakan bahwa media dapat 
menjadi penyebab terjadinya stagnasi pada pertumbuhan tanaman, karena suatu sel dapat atau tidak terdorong melakukan proses pembelahan dari kondisi media tersebut.

Selain media, kemungkinan besar faktor lain yang menyebabkan stagnasi pada tunas yaitu umur kalus yang digunakan sudah berkurang daya regenerasinya. Menurut Purmaningsih (2006) lamanya waktu (hari) dari awal kalus diinduksi sampai kalus dipindahkan ke media regenerasi sangat menentukan frekuensi regenerasi. Hal ini mungkin terjadi, namun pada penelitian ini kalus yang digunakan merupakan kalus yang baru terbentuk karena proses pembesaran kalus. Menurut Lestari \& Yunita (2008), kalus yang baru terbentukakan berpeluang menghasilkan tunas lebih tinggi dibandingkan kalus yang telah disubkultur berkali kali, karena pada kalus yang baru terbentuk kandungan poliamin atau senyawa yang berperan dalam sistem regenerasi masih tinggi. Kalus yang mengalami stagnasi sampai akhir pengamatan, menunjukkan pertumbuhan tunas yang lambat atau bahkan tidak mengalami penambahan tinggi tunas.

\section{Pertambahan Diameter Kalus}

Pada fase pemeliharaan kalus Cucumis sp., menghasilkan adanya pembentukan kalus baru yang berbentuk remah dan berwarna kehijauan. Hal ini diduga karena kalus embrionik (proembrionik) terus membelah diri dan membentuk kembali sel-sel yang proembrionik. Pengukuran diameter kalus dilakukan setiap 3 hari selama 2 bulan menggunkan penggaris dapat dilihat pada Tabel 5.

Tabel 5. Rata-rata pertambahan diameter kalus pada beberapa perlakuan selama penelitian berlangsung (hsi)

\begin{tabular}{cccccc}
\hline & $\begin{array}{c}\text { Konsentrasi } \\
\text { BAP }(\mathbf{B})\end{array}$ & $\begin{array}{c}0,0 \mathrm{ppm} \\
\left(\mathrm{N}_{0}\right)\end{array}$ & $\begin{array}{c}0,15 \mathrm{ppm} \\
\left(\mathrm{N}_{1}\right)\end{array}$ & $\begin{array}{c}0,20 \mathrm{ppm} \\
\left(\mathrm{N}_{2}\right)\end{array}$ & $\begin{array}{c}0,25 \mathrm{ppm} \\
\left(\mathrm{N}_{3}\right)\end{array}$ \\
\cline { 2 - 6 } Rata-rata & $0,0 \mathrm{ppm}\left(\mathrm{B}_{0}\right)$ & - & - & - & 0.76 \\
Pertambahan & $1,0 \mathrm{ppm}\left(\mathrm{B}_{1}\right)$ & - & - & 0.88 & - \\
Diameter & $1,5 \mathrm{ppm}\left(\mathrm{B}_{2}\right)$ & - & - & - & - \\
Kalus $(\mathbf{c m})$ & $2,0 \mathrm{ppm}\left(\mathrm{B}_{3}\right)$ & - & 1.14 & - & 0.79 \\
& $2,5 \mathrm{ppm}\left(\mathrm{B}_{4}\right)$ & - & - & - & 1.28 \\
& $3,0 \mathrm{ppm}\left(\mathrm{B}_{5}\right)$ & 1.37 & - & - & 1.53 \\
\hline
\end{tabular}

Keterangan : (-) tidak ada pertambahan diameter kalus

Pada Tabel 5. Perlakuan $\mathrm{B}_{5} \mathrm{~N}_{3}(3,0$ ppm $\mathrm{BAP}+0,25$ ppm NAA) merupakan perlakuan yang menghasilkan rata-rata pertambahan diameter yang paling besar. Pada dasarnya perubahan diameter kalus menunjukkan eksplan yang ditanam masih hidup (Toharah et al., 2015). Pada perlakuan $\mathrm{B}_{3} \mathrm{~N}_{1}\left(2,0 \mathrm{ppm} \mathrm{BAP}+0,15\right.$ ppm NAA) dan $\mathrm{B}_{5} \mathrm{~N}_{3}(3,0$ ppm BAP +0,25 ppm NAA) muncul spot hijau pada 39 hsi. Spot hijau ini hanya terbentuk dan tidak ada perkembangan kearah tunas. 
Menurut Lestari \& Yunita (2008), kemungkinan besar munculnya spot hijau tetapi tidak ada perkembangan tunas diakibatkan karena keseimbangan konsentrasi dan jenis ZPT yang digunakan belum sesuai dengan tanaman yang digunakan, sehingga belum mampu menginduksi munculnya tunas secara optimal. Spot berwarna hijau pada kalus (Gambar 4) pada umumnya akan berubah warna menjadi coklat bila tidak segera disubkultur pada media baru atau akan terjadi dediferensiasi dimana massa sel terus membelah dan tidak terorganisasi.

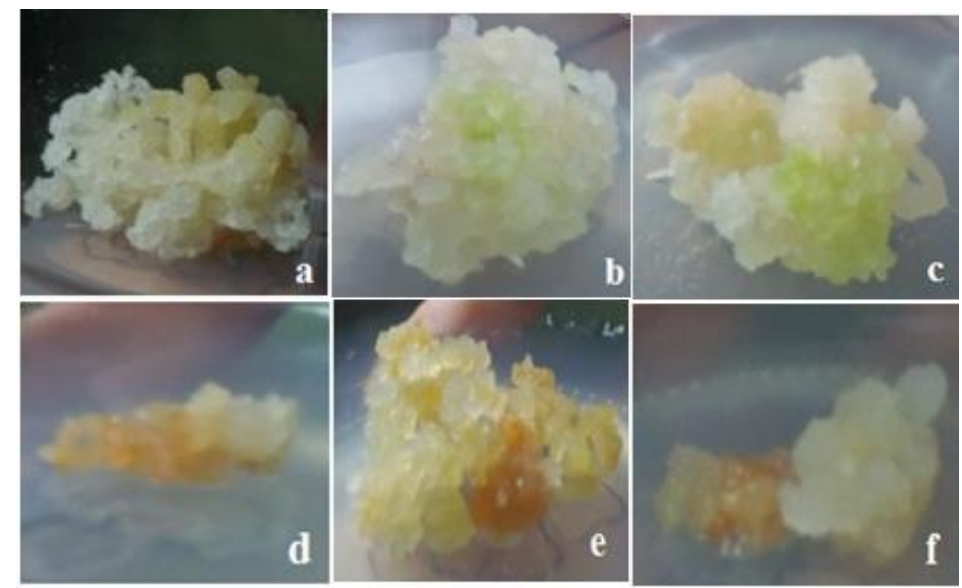

Gambar 5. Diameter kalus membesar pada beberapa perlakuan saat $60 \mathrm{HSI}, \mathrm{a} \mathrm{B}_{4} \mathrm{~N}_{3}(2,5 \mathrm{ppm}$ BAP + 0,25 ppm NAA $)$, b. $B_{5} \mathrm{~N}_{3}(3,0 \mathrm{ppm}$ BAP + 0,25 ppm NAA $)$, c. $B_{3} \mathrm{~N}_{1}(2,0 \mathrm{ppm}$ BAP + 0,15 ppm NAA), d. $B_{0} \mathbf{N}_{3}(0,25$ ppm NAA $)$, e. $B_{5} \mathbf{N}_{0}(3,0 \mathrm{ppm}$ BAP $)$, f. $\mathrm{B}_{1} \mathrm{~N}_{2}$ $(1,0$ ppm BAP + 0,20 ppm NAA)

Menurut Ningsih et al. (2016), bertambahnya diameter kalus pada penelitian ini (Gambar 5) kemungkinan dapat disebabkan oleh faktor genetik, kemungkinan genotipe yang digunakan saat penelitian memiliki daya regenerasi yang rendah, sehingga kalus terus bertambah ukuran tanpa adanya inisiasi kearah tunas. Kemungkinan besar juga karena keseimbangan NAA dan BAP yang digunakan belum sesuai untuk pertumbuhan tunas.Sujatmiko et al. (2012) menyatakan bahwa penggunaan sitokinin dalam jumlah besar seperti BAP maupun thidiazuron secara eksogen dapat mengubah keseimbangan hormon tanaman sehingga sel-sel tidak terdiferensiasi dengan teratur menyebabkan pembentukan kalus. Menurut Keng \& Hoong (2006), penambahan auksin NAA meningkatkan pembentukan kalus yang friable pada eksplan buku muskmelon, sedangkan penambahan konsentrasi sitokinin yang semakin meningkat menghasilkan warna hijau pada kalus lebih tahan lama. Ariani et al. (2016) menyatakan bahwa tingkat pencahayaan yang tercukupi merupakan salah satu faktor kalus-kalus tersebut dapat berubah warna menjadi hijau. Perubahan warna hijau pada kalus menandakan bahwa kalus tersebut dapat melangsungkan fotosintesis dan dimungkinkan mengandung banyak pigmen klorofil. Salah satu tanda bahwa 
kalus beregenerasi dengan baik dan sel-selnya masih terus aktif membelah adalah perubahan warna hijau pada dan kalus yang terbentuk juga memiliki ukuran yang cukup besar.

\section{SIMPULAN}

Konsentrasi kombinasi terbaik ditunjukkan pada 2,5 ppm BAP + 0,20 ppm NAA $\left(\mathrm{B}_{4} \mathrm{~N}_{2}\right)$ yang memberikan pertumbuhan optimal terhadap tinggi tunas timun apel sebesar $0,45 \mathrm{~cm}$ dan waktu awal muncul tunas sebesar 33 hsi serta memiliki warna tunas kuning (skoring 3). Perlakuan tunggal $\mathrm{B}_{1} \mathrm{~N}_{0}(1 \mathrm{ppm} \mathrm{BAP}$ ) dari kalus tanaman timun apel (Cucumis sp.) juga menghasilkan waktu awal muncul tunas tercepat sebesar 24 hsi dan tinggi tunas terbaik sebesar $0,5 \mathrm{~cm}$ tetapi warna tunas yang terbentuk adalah warna putih (skoring 2).Perlakuan yang menghasilkan pertambahan diameter yang paling besar ada pada perlakuan $\mathrm{B}_{5} \mathrm{~N}_{3}(3,0$ ppm BAP $+0,25$ ppm NAA) yang menghasilkan rata-rata pertambahan diameter sebesar $1,53 \mathrm{~cm}$. Hasil penelitian ini juga menunjukan bahwa kemungkinan besar penggunaan media gamborg (B5) pada tanaman timun apel (Cucumis sp.) ternyata membutuhkan asam amino glycine untuk pertumbuhan tunas secara organogenesis tidak langsung agar pertumbuhan tunas lebih optimal.

\section{DAFTAR PUSTAKA}

Ardiana, D.W. (2009).Teknik Pemberian Benzil Amino Purin untuk Memacu Pertumbuhan Kalus dan Tunas pada Kotiledon Melon (Cucumis melo L.). Buletin Teknik Pertanian, 14(2), 50-53.

Ariani, Anggraito, \& Rahayu. (2016). Respon Pembentukan Kalus Koro Benguk (Mucuna Pruriens L.) pada Berbagai Konsentrasi 2,4-D dan BAP. Jurnal MIPA, 39(1), 20-28.

Arimarsetiowati, R. (2012). Kultur Jaringan Tanaman Kopi. Pusat Penelitian Kopi dan Kakao Indonesia, 13-17.

Ayu, R. (2019). Pengaruh Kombinasi Konsentrasi NAA dan BAP Terhadap Induksi Embrio Somatik Timun Apel (Cucumis sp.) Pada Kultur in vitro dengan Teknik Pendinginan. Skripsi. Karawang: Universitas Singaperbangsa Karawang.

Fauzy, E., Mansyur, \& Husni, A. (2016). Pengaruh Penggunaan Media Murashige dan Skoog (MS) dan Vitamin Terhadap Tekstur, Warna dan Berat Kalus Rumput Gajah (Pennisetum Purpureum) Cv. Hawaii Pasca Radiasi Sinar Gamma Pada Dosis LD 50 (in vitro). Students e-Journal, 5(4).

Furqon, P. D. (1999). Statistika terapan untuk penelitian. Alfabeta, Bandung.

Karjadi, A. K., \& Buchory, A. (2007). Pengaruh NAA dan BAP terhadap pertumbuhan jaringan meristem bawang putih pada media B. Jurnal Hortikultura, 17(3), 217-223. 
Keng, C. L., \& Hoong, L. K. (2006). In vitro plantlets regeneration from nodal segments of muskmelon (Cucumis melo L.). Biotechnology, 4, 354-357.

Khalida, A., \& Noli, S. Z. (2019). Induksi Kalus Anggrek Lilin (Aerides odorata L.) dengan Pemberian beberapa Konsentrasi 2,4 Diklorofenoksiasetat (2,4 D). Jurnal Biologi Universitas Andalas, 7(2), 109-117.

Kristanti, I., Habibah, N.A., \& Herlina, L. (2013). Optimasi Konsentrasi 2,4-D, Ba, dan Lama Penyinaran untuk Memacu Regenerasi Tunas dari Kalus Kedelai. Biosaintifika, $5(1)$.

Kurniawan, R., Hasibuan, S., \& Mawarni, R. (2019). Efek Kombinasi BAP dan NAA Terhadap Morfogenensis Eksplan Pelepah Gandum (Triticum aestivum) secara in vitro. Agricultural Research Journal, 15(1).

Lestari, A., Azizah, E., Sulandjari, K., \& Yasin, A. (2018). Pertumbuhan miselia jamur merang (Volvariella volvaceae) lokasi pacing dengan jenis media dan konsentrasi biakan murni secara in vitro. Jurnal Agro, 5(2), 114-126.

Lestari, E. G., \& Yunita, R. (2008). Induksi kalus dan regenerasi tunas padi varietas Fatmawati. Jurnal Agronomi Indonesia (Indonesian Journal of Agronomy), 36(2).

Lidyawati, N. N., Waeniati, W., Muslimin, M., \& Suwastika, I. N. (2012). Perbanyakan Tanaman Melon (Cucumis melo L.) Secara in vitro pada Medium MS dengan Penambahan Indole Acetic Acid (IAA) dan Benzil Amino Purin (BAP). Natural Science: Journal of Science and Technology, 1(1).

Mufidah, F. (2018). Analisis Karakter Kuantitatif Tanaman Timun Apel dengan Jarak Tanam yang Berbeda di Pakisjaya Karawang. Skripsi. Karawang: Universitas Singaperbangsa Karawang.

Muliati, Nurhidayah, T., \& Nurbaiti. (2017). Pengaruh NAA, BAP dan Kombinasinya Pada Media MS Terhadap Perkembangan Eksplan Sansevieria macrophyllasecara secara in vitro. Jom Faperta, 4(1).

Ningsih, R., Purwoko, B. S., Syukur, M., \& Dewi, I. S. (2016). Induksi kalus dan regenerasi tiga genotipe tomat (Solanum lycopersicon L.) melalui kultur antera. Jurnal Hortikultura Indonesia, 7(2), 75-82.

Paramartha, A. I., Ermavitalini, D., \& Nurfadilah, S. (2012). Pengaruh penambahan kombinasi konsentrasi ZPT NAA dan BAP terhadap pertumbuhan dan perkembangan biji Dendrobium taurulinum JJ Smith secara in vitro.Jurnal Sains dan Seni ITS, 1(1), 40-43.

Prayoga, L., \& Sugiyono, S. (2010). Uji Perbedaan Media dan Konsentrasi BAP terhadap Pertumbuhan Tunas Pisang Raja secara Kultur in vitro. Agritech: Jurnal Fakultas Pertanian Universitas Muhammadiyah Purwokerto, 12(2). 
Purita, S.Y., Ardiarini, N.R., \& Basuki, N. (2017). Pengaruh Zat Pengatur Tumbuh Jenis BAP terhadap Pertumbuhan Planlet Sub Kultur Jaringan tanaman Nanas (Ananas comosus L. Merr). Jurnal Produksi Tanaman, 5(7), 1207-1212.

Purnamaningsih, R. (2002). Regenerasi tanaman melalui embriogenesis somatik dan beberapa gen yang mengendalikannya. Buletin AgroBio, 5(2), 51-58.

Purnamaningsih, R. (2006). Induksi Kalus dan Optimasi Regenerasi Empat Varietas Padi melalui Kultur in vitro. Jurnal AgroBio, 2(2): 74-80.

Rohayati. (2012). Pembentukan Tunas Aksiler dan Adventif Philodendron Kultivar Moon Light pada Berbagai Media Regenerasi. Buletin Teknik Pertanian, 17(1), 30-32.

Romeida, A., Sutjahjo, S. H., Purwito, A., \& Sukma, D. (2013). Optimasi Pertumbuhan dan Multiplikasi Lini Klon PLBs Anggrek Spathoglottis plicata Blume melalui Modifikasi Komposisi Medium MS dan Sitokinin. Jurnal Hortikultura Indonesia, 4(1), 1-8.

Rosmaina \& Aryani, D. (2015). Optimasi NAA dan BAP terhadap Pertumbuhan dan Perkembangan Tunas Mikro Tanaman Kantong Semar (Nepenthes mirabilis) secara in vitro. Jurnal Agroteknologi, 5(2), 29-36

Saptari, R. (2017). Organogenesis untuk Perbanyakan Tanaman Hias. Indonesian Research Institute for Biotechnology and Bioindustry, 5(1), 18-20.

Saputro, N. W., Hidayat, T., Bayfurqon, F. M., \& Khamid, M. B. R. (2020). Evaluation of Morpho-Agronomic Characterization Apple Cucumber: A New Variety of Melon From Indonesia. E\&ES, 457(1).

Siegel, S., Suyuti, Z., \& Simatupang, L. (1997). Statistik Nonparametrik untuk Ilmu-Ilmu Sosial. Jakarta: Gramedia.

Sisharmini, Apriana, \& Sustiprijatno. (2010). Induksi Kalus dan Regenerasi Beberapa Genotipe Gandum (Triticum aestivum L.) secara in vitro. Jurnal AgroBiogen, 6(2), 5764.

Sujatmiko, B., Sulistyaningsih, E., \& Murti, R. H. (2012). Studi Ketahanan Melon (Cucumis melo L.) Terhadap Layu Fusarium Secara in vitro dan Kaitannya dengan Asam Salisilat. Ilmu Pertanian (Agricultural Science), 15(2), 1-18.

Souza, F. V. D., Garcia-Sogo, B., Souza, A. D. S., San-Juán, A. P., \& Moreno, V. (2006). Morphogenetic Response of Cotyledon and Leaf Explants of Melon (Cucumis melo L.) cv. Amarillo Oro. Brazilian Archives of Biology and Technology, 49(1), 21-27.

Sucandra, A., Silvina, F., \& Yulia, A. E. (2015). Uji Pemberian Beberapa Konsentrasi Glisin Pada Media Vacin and Went (VW) terhadap Pertumbuhan Plantlet Anggrek (Dendrobium sp.) secara in vitro. Jom Faperta, 2(1).

Surachman, D. (2011). Teknik Pemanfaatan Air Kelapa untuk Perbanyakan Nilam Secara In Vitro. Buletin Teknik Pertanian, 16(1), 31-33. 
Jurnal Mangifera Edu, Volume 5, Issue 2, January 2021, 103-120

Syabana, M. A., Marianingsih, P., Hermita, N., \& Rohimah, I. (2017). Induksi dan Pertumbuhan Kalus Tanaman Stevia (Stevia Rebaudiana Bertoni M.) dengan Perbedaan Konsentrasi PEG (Polyethylene Glycol) pada Kondisi Pencahayaan secara In Vitro. Biodidaktika, 12(2), 57-68.

Toharah, N.I., Dwi, S.D.J., \& Lalu, Z. (2015). Pertumbuhan Kalus Daun Melon (Cucumis melo) Varietas MAI 119 dengan Pemberian BAP (Benzyl Amino Purine) dan 2.4 D (2.4 Dichlorophrmoxyacetic Acid). Jurnal Penelitian Pedidikan IPA, 1(2), 39-47.

Tyas, K. N., Susanto, S., Dewi, I. S., \& Khumaida, N. (2016). Organogenesis Tunas secara Langsung pada Pamelo (Citrus maxima (Burm.) Merr.). Buletin Kebun Raya, 19(1), 01-10.

Ubudiyah, I. W. A., \& Nurhidayati, T. (2013). Respon Kalus Beberapa Varietas Padi (Oryza sativa L.) pada Kondisi Cekaman Salinitas $(\mathrm{NaCl})$ secara In Vitro. Jurnal Sains dan Seni ITS, 2(2), 138-143.

Widyastuti, K. (2017). Pengaruh Kombinasi NAA (Naphtalene Acetic Acid) dan BAP (Benzil Amino Purine) terhadap Induksi Tunas Aksilar Tanaman Balsam (Polygala paniculatal). Secara in vitro. Skripsi. Malang: Universitas Islam Negeri Maulana Malik Ibrahim.

Widyawati, G. (2010). Pengaruh Variasi Konsentrasi NAA dan BAP terhadap Induksi Kalus jarak Pagar (Jatropha curcas L.). Tesis. Surakarta: Universitas Sebelas Maret.

Yuniati, F., Haryanti, S., \& Prihastanti, E. (2018). Pengaruh hormon dan ukuran eksplan terhadap pertumbuhan mata tunas tanaman pisang (Musa paradisiaca var. Raja Bulu) secara in vitro. Buletin Anatomi dan Fisiologi (Bulletin of Anatomy and Physiology), 3(1), 20-28. 